\title{
Jokie Bakker and Ronald J. Clarke: Wine Flavour Chemistry (2nd Edn)
}

\author{
Edward R. Adlard ${ }^{1}$
}

๑) Springer-Verlag GmbH Germany, part of Springer Nature 2018

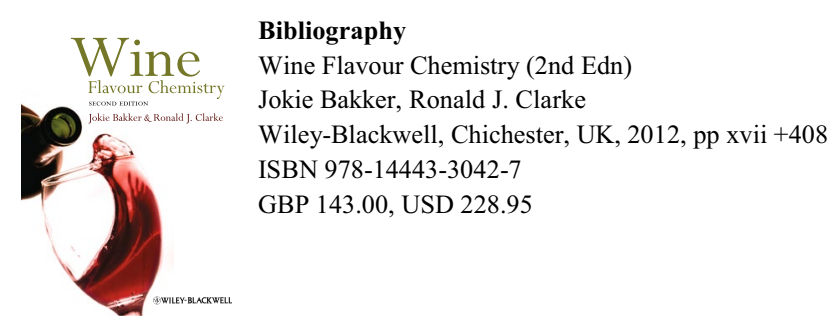

This book was originally published in 2012 but the publisher sent me a copy recently and I thought it of sufficient importance and relevance to warrant a review now.

An early exponent of the then new technique of gas-liquid chromatography was the late Professor Ernst Bayer (1927-2002) who applied it to the study of wine and it is appropriate that a review of this volume should appear in a journal of German origin, founded by Rudolph E. Kaiser, and published by Springer verlag.

The importance of chromatography for this work is summarised on page 156 where it states "As a result of sophisticated analytical procedures using gas chromatography... over 400 compounds have now been detected and many of these quantified...". However, there is much more in this book than GC and the six chapters cover a multitude of topics. The first introductory chapter covers the whole spectrum in 52 pages, ending (like all the following chapters) with a bibliography and references. This introduction gives the topics which are discussed in greater detail in the following chapters; Chapter 2 is headed Grape Varieties and Growing Regions. Climate warming is altering the latter, so that wine is now produced in significant amounts in England, a thing which would have been unheard of until relatively recently. The surprising thing (to me at least) was that relatively few varieties account for the great majority of wines on the market, for example, most German white wines are made from Riesling grapes. The next chapter entitled "Basic Taste and Stimulant Components" describes some of the many organic compounds which may be present in wine including of course ethanol, sugars and a host of other compounds such as flavonoids and anthocyanins. Analytical methods including HPLC and NMR are mentioned briefly and inorganic compounds such as $\mathrm{SO}_{2}$ and oxygen round off this chapter.

The title of the next chapter "Volatile Components" may seem something of a misnomer, since ethanol is the "volatile component" par excellence. However, the chapter covers a multitude of compounds falling into the category of volatile, including aldehydes, ketones, esters and numerous other alcohols besides ethanol. This chapter is a chemist's paradise in terms of the range and number of compounds described, going back to the statement on page 156 quoted above. The penultimate chapter on "Wine Tasting Procedures and Overall Wine Flavour" might be entitled, to paraphrase Hamlet, "To spit or not to spit" and gives information for the wine connoisseur about the glass to use, the aroma, colour, etc. The final chapter covers the subject of fortified wines such as sherry and port.

Overall, this book is a must for those involved in the analysis of wine and for those like me who enjoy a glass of wine without worrying too much about anything else.

Edward R. Adlard

e.adlard77@btinternet.com

1 Burton, UK 